specimens containing 40 per cent. of autunite, obtained direct from the mining syndicate, having been ground up together. From a fresh batch, obtained through a dealer, two single pieces were picked out, the first being an almost pure crystal. weighing 2.3 grams, and of so fresh and new appearance that it looked as if it had been withdrawn from its mother-liquor but yesterday, and the second an obviously older looking, greener, and much larger mass containing 46 per cent. of matrix. The first gave a radium ratio of 70 per cent., and in it helium could not be detected. The quantity was not greater than $0.002 \mathrm{cu}$. $\mathrm{mm}$. per gram U. This quantity would form in about thirty years! For the second, the radium ratio was 44 per cent. and the helium $0.035 \mathrm{cu}$. $\mathrm{mm}$. per gram $\mathrm{U}$, which would be produced in about 600 years. Lastly, $\mathrm{Mr}$. Russell very kindly gave me the remains of the specimen for which he found 27 per cent. for the radium ratio. It weighed less than 0.5 gram, but the helium was easily detectable. It amounted to more than $0.15 \mathrm{cu} . \mathrm{mm}$. per gram $\mathrm{U}$, some being lost.

If these results are representative, the radium ratio decreases to a minimum and then rises more slowly as the helium content increases. If the latter is taken as a measure of the age of the mineral, the minimum appears to be reached after a few thousand years. This, of course, is exactly what would occur if, when the autunite was formed, the radium (but not its parent) associated with the uranium in its former condition separated with the latter. This in itself is not only possible, but probable, owing to the isomorphism of radium and calcium. But it is a somewhat startling result if initial radium can have any influence on the amount present in a mineral to-day, for this necessitates that the ages indicated by the helium content are not altogether below the truth, and that these beautiful crystals are actually even now in full process of formation.

Physical Chemistry Laboratory, University of

$$
\text { Glasgow. }
$$

\section{Stagnant Glaciers}

IN the notice of the Professional Papers of the U.S. Geological Survey on the "Glaciers, Goldfields, and Landslides of North America," published in NATURE of July $2 \mathrm{I}$, attention is directed to the peculiar stagnant condition of some glaciers, and to the fact that certain glaciers, after being stagnant for long intervals, suddenly commence to move.

Although the movement of glaciers is such as would take place if they were viscous bodies, there is reason to believe that they have not all the same viscosity. I pointed out in a paper communicated to the Royal Society (Proc. Roy. Soc., 1908, p. 250) that the calculated viscosities of several Swiss glaciers varied from $292 \cdot 2 \times 10^{12}$ to $3.17 \times 10^{12}$ C.G.S. units. Although some of the data upon which these figures were based were only estimated ones, I do not think that the different viscosities found are due wholly to errors in the data. In other words, that the viscosity of glacier ice is not a constant, as in the case of water, \&c., but varies with variations in the granular structure of the ice, or that there is a limiting stress below which distortion does not take place as with plastic bodies.

So far as I am aware, no glaciers have been proved actually to be stagnant by careful measurement. Generally speaking, the conclusion that a glacier is dead is formed owing to the absence of certain features which are generally associated with glacier movement.

It is very desirable that such statements should be based upon actual measurements only, and also that the actual granular structure of the ice should be given, for there is every reason to believe that the viscosity of glacier ice varies with the size of the glacier grains. Were it not for the fact that the glacier grains are actually broken up by shear planes in the ice, they would gradually become larger and larger until they became so large, and the viscosity beçame so great, that the ice would scarcely move at all on small slopes. In such a case an earthquake might give rise to fractures in the ice, and by temporarily decreasing the viscosity increase the rate of flow.

R. M. DEELEY.

Melbourne House, Osmaston Road, Derby, July 23. NO. 2 I 32 , VOL. 84$]$
IT chanced, strangely enough, that Mr. Deeley's interesting letter reached me at a Norwegian port during the return journey of the Geological Congress party from Spitsbergen, on which Prof. R. S. Tarr, whose work has given rise to the letter, is a fellow-traveller with me. I have therefore taken advantage of the opportunity to discuss the subject with Prof. Tarr and other glacialists of our party.

Mr. Deeley is right in his supposition that the stagnant condition of the "dead ice" in Alaska has been inferred from surface indications, and has not yet been tested by actual measurement. It is, indeed, not likely that the ice of the areas described as "stagnant" is absolutely motionless, nor do $I$ think that this has been implied in the descriptions. Such motion as it may have must however be very small, since it seems that the trees covering parts of the surface-moraines in the "dead" areas show no sign of disturbance.

As hinted in my review, it is evident that rapid advances of glaciers, comparable to those observed in Alaska, have taiken place in regions where some other cause than an earthquake must be sought. During our recent journey in Spitsbergen, of which I hope shortly to give some account in these pages, we have been shown by our leader, Prof. G. de Geer, several cases of this kind which he has studied. It may be that Mr. Deeley's explanation of ice-structure will explain these rapid spasmodic movements, but I shall not venture upon a discussion of this difficult physical question. Mr. Deeley has at any rate suggested a line of research which ought to be followed up and experimentally tested in the field.

Stockholm, August 19.

G. W. Lamplugh.

\section{The Leaning Tower of Pisa.}

THE photograph of the "Leaning" Tower of Pisa in NATURe of August 4 shows clearly that the top tier is not square with the rest. From a rough alignment with the edge of a postcard, the photograph appears as if the tower was of the order of $25 \mathrm{~mm}$. / metre out of plumb when the top tier was put on presumably plumb.

Exact measures of this and of other parts of the tower might afford interesting data as to the epochs of the construction of the tower and of the progress of its "leaning."

EDWARD G. BRown.

THIs famous tower will doubtless always be a question, like the man in the iron mask and other historical mysteries. Most architects, however, will be very slow to believe that it would have been built intentionally leaning on the general grounds that, however adventurous the architect, the clients would not have stood it. The analogy of the leaning towers of Bologna is hardly a sound one, as these plain shafts of brickwork, much like tall chimneys, can hardly be other than cases of settlement due to indifferent foundations. It should be remembered that construction was not a strons point with the Italians in the Middle and Renaissance Ages. In the case of the Tower of Pisa, Taylor particularly remarks on the wedge-shaped courses, which show an attempt to straighten the shaft. The best explanation appears to be that the tower was commenced, settled on its marshy bed, and that when the building was continued after a long interval it was considered safe to continue the work up to the limit of stability which could be calculated by the mathematicians of the epoch. The overhang is given by Taylor as $I_{3}$ feet.

It is rather a pity that so much attention is concentrated by visitors on the tower, whereas the cathedral, Campo Santo, and particularly the Baptistery, are monuments of greater architectural importance. The design of the Baptistery is extremely interesting, and is perhaps the nearest expression of a Gothic dome.

The construction in this case is highly interesting because the outer dome is supported by a cone, as at St. Paul's, London, but without an inner dome. As, however, the cone is not illuminated from the inside, it has a domical effect. The top of the cone shows externally. to the detriment of the general outline, not being cut off to carry a lantern as at St. Paul's. 